Research paper

\title{
Responses of anaerobic microorganisms to different culture conditions and corresponding effects on biogas production and solid digestate quality
}

\author{
Rui Chen a, Mariana Murillo Roos ${ }^{\mathrm{g}}$, Yuan Zhong a , Terence Marsh ${ }^{\mathrm{b}}$, \\ Mauricio Bustamante Roman ${ }^{a}$, Walter Hernandez Ascencio ${ }^{c}$, Lidieth Uribe ${ }^{\mathrm{f}}$, \\ Lorena Uribe Lorio ${ }^{c}$, Dana Kirk ${ }^{a}$, Dawn Marie Reinhold ${ }^{a}$, \\ Jose Alberto Miranda Chavarria d, Daniel Baudrit Ruiz ${ }^{\mathrm{d}}$, Jose Francisco Aguilar Pereira ${ }^{\mathrm{d}}$, \\ Werner Rodriguez Montero ${ }^{\mathrm{e}}$, Ajit Srivastava ${ }^{\mathrm{a}}$, Wei Liao ${ }^{\text {a, * }}$ \\ ${ }^{a}$ Biosystems and Agricultural Engineering, Michigan State University, East Lansing, MI, USA \\ ${ }^{\mathrm{b}}$ Microbiology and Molecular Genetics, Michigan State University, East Lansing, MI, USA \\ ${ }^{c}$ Research Center for Cellular and Molecular Biology, University of Costa Rica, San Jose, Costa Rica \\ ${ }^{\mathrm{d}}$ Agricultural Engineering, University of Costa Rica, San Jose, Costa Rica \\ e Fabio Baudrit Experimental Station, University of Costa Rica, San Jose, Costa Rica \\ ${ }^{\mathrm{f}}$ Agronomy Research Center, University of Costa Rica, San Jose, Costa Rica \\ ${ }^{g}$ National Institute for Innovation and Transfer of Agricultural Technology, Ministry of Agriculture, San Jose, Costa Rica
}

\section{A R T I C L E I N F O}

\section{Article history:}

Received 15 April 2015

Accepted 27 November 2015

Available online 17 December 2015

\section{Keywords:}

Anaerobic microbes

Co-digestion

Biorefining feedstock

Biogas

Solid digestate

\begin{abstract}
A B S T R A C T
Microbial communities of anaerobic digestion have been intensively investigated in the past decades. Majority of these studies focused on correlating microbial diversity with biogas production. The relationship between microbial communities and compositional changes of the solid digestate (AD fiber) has not been comprehensively studied to date. Therefore, the objective of this study was to understand the responses of microbial communities to different operational conditions of anaerobic co-digestion and their influences on biogas production and solid digestate quality. Two temperatures and three manureto-food waste ratios were investigated by a completely randomized design. Molecular analyses demonstrate that both temperature and manure-to-food waste ratio greatly influenced the bacterial communities, while archaeal communities were mainly influenced by temperature. The digestion performance showed that biogas productivity increased with the increase of supplemental food wastes, and there were no significant differences on carbohydrate contents among different digestions. The statistical analyses conclude that microbes changed their community configuration under different conditions to enhance digestion performance for biogas and homogenized solid digestate production.
\end{abstract}

(C) 2015 Elsevier Ltd. All rights reserved.

\section{Introduction}

Anaerobic digestion (AD) is one of the oldest biotechnologies that mankind has practiced to treat organic wastes for several centuries. A complex anaerobic microbial consortium converts organic matter in the wastes into methane biogas - a carbon neutral and renewable energy source, and correspondingly alleviates the

\footnotetext{
* Corresponding author. Michigan State University, 524 S. Shaw Ln, Room 202, East Lansing, MI 48824, USA.
}

E-mail address: liaow@msu.edu (W. Liao). odor and pathogen problems. The classic AD systems often used animal manure or sewage sludge as feedstock to provide nutrients and inoculate anaerobic microorganisms [1]. However, due to the structural and nutritional limitation of manure and sludge, singlesourced AD systems have been described as "not energy efficient nor cost effective" [2]. Co-digestion of multiple feedstocks was hence introduced to enhance $\mathrm{AD}$ performance of biogas production and total solids (TS) reduction [3-5]. In addition, the overall performance of an $\mathrm{AD}$ system depends on not only the composition of feedstock, but also operational parameters such as temperature [6]. Conventional operational temperatures range from mesophilic $\left(30-38^{\circ} \mathrm{C}\right)$ to thermophilic $\left(49-57^{\circ} \mathrm{C}\right)$, and it has been proven that 
operational temperature is one of the most important determinants of the microbial community structure in an AD system [6,7].

Numerous studies have been conducted on the microbiology of anaerobic co-digestion system to correlate biogas production with microbial diversity [8-12]. However, the relationship between microbial communities and compositional changes of the solid digestate (AD fiber) has not been widely reported [13]. Several recent studies have discovered that solid digestate has a similar cellulose conversion potential with other energy crops and residues such as switchgrass and corn stover, and it can be used as a cellulosic feedstock for biorefining of fuel and chemical production [14-18]. Therefore, a clear understanding on the relationship between mixed feedstock, microbial communities, biogas production, and solid digestate quality should be achieved in order to advance $\mathrm{AD}$ technology into a pretreatment unit operation for the nextgeneration fuel and chemical biorefining.

The objective of this study was to delineate the responses of microbial communities to changes in substrate composition and reaction temperature of anaerobic co-digestion. Dairy manure was mixed with food waste as the substrates to feed anaerobic digesters. The 16S rRNA gene-based 454 pyrosequencing, Terminal Restriction Fragment Length Polymorphism (T-RFLP) and clone library were used to investigate the communities. Microbial communities was also statistically correlated with performance parameters such as TS reduction, biogas production, and AD fiber quality (cellulose, xylan, and lignin).

\section{Materials and methods}

\subsection{Feedstock}

Fresh dairy manure was collected from the Michigan State University dairy farm $\left(42^{\circ} 41^{\prime} 53.80^{\prime \prime} \mathrm{N}, 84^{\circ} 29^{\prime} 8.63^{\prime \prime} \mathrm{W}\right)$, and stored at $-20{ }^{\circ} \mathrm{C}$ prior to use. Dairy cows were fed on an alfalfa and corn silage blend diet formulated according to the standard Total Mixed Rations (TMRs) [19]. Food waste collected from cafeterias on campus was homogenized using a commercial immersion blender (Waring WSB70, Waring, Stamford, CT) and stored at $-20^{\circ} \mathrm{C}$ prior to use.

\subsection{Anaerobic digestion systems}

A completely stirred tank reactor (CSTR) was used as the anaerobic digester in this study. Three different weight ratios of dairy manure to food waste were used as feeds for the anaerobic digesters: 100:0, 90:10 and 80:20 (based on dry weight). Each digester contained $5 \% \mathrm{TS}$. Two culture temperatures of 35 and $50{ }^{\circ} \mathrm{C}$ were tested. The hydraulic retention time (HRT) was 20 days. A completely randomized design (CRD) was applied on both factors of manure-to-food waste ratio and temperature. Six treatments with replicates were cultured on New Brunswick shakers (Eppendorf, Enfield, CT) at $150 \mathrm{rpm}$ for 4 full HRTs (80 days). All digesters had a working volume of $0.50 \mathrm{~L}$ with $0.25 \mathrm{~L}$ headspace. The digesters were first purged with nitrogen gas for $30 \mathrm{~s}$ and then sealed with rubber septum caps. Daily biogas accumulation was measured using a water displacement system. Biogas sample from the digesters was collected for gas composition analysis. All digesters were fed every other day with $50 \mathrm{~mL}$ of afore mentioned feed. Feed was prepared a few days before the feeding according to the manure-to-food waste ratios, and stored at $4{ }^{\circ} \mathrm{C}$. Prior to the feeding, an equal volume $(50 \mathrm{~mL})$ of digestate was removed from the digesters as the digestate samples: $40 \mathrm{~mL}$ of the digestate samples were stored at $-20{ }^{\circ} \mathrm{C}$ for TS, cellulose, xylan, and lignin analyses. $10 \mathrm{~mL}$ of the digestate samples were stored at $-80^{\circ} \mathrm{C}$ for microbial community analysis. The $\mathrm{pH}$ of all digesters was controlled above 6.70 by dosing $20 \%$ sodium hydroxide $(\mathrm{NaOH})$ at the start-up stage of digestion (first one to two weeks). The operations of sampling, feeding, and $\mathrm{pH}$ adjustment were carried on using a Simplicity 888 automatic anaerobic chamber (PLAS Lab, Lansing, MI) purged with a medical grade specialty gas (85\% nitrogen, $10 \%$ hydrogen and $5 \%$ carbon dioxide).

\subsection{Analytical methods}

Methane and carbon dioxide content were quantified using a SRI 8610c gas chromatograph (Torrance, CA). The system was equipped with a thermal conductivity detector. The detector was kept at $150{ }^{\circ} \mathrm{C}$ during the analysis. Hydrogen and helium were carrier gases, and maintained at $21 \mathrm{psi}$. The biogas sample volume was $100 \mu \mathrm{L}$, and the syringe was purged three times before sample injection. Fiber composition of the digestate was analyzed according to the National Renewable Energy Laboratory (NREL) Analytical Procedure (LAP) [20]. The free sugars and starch was analyzed using a commercial starch assay kit (Catalog No. SA20. Sigma-Aldrich Co. LLC, St. Louis, MO).

\subsection{Bacterial community analysis}

A Power-Soil DNA isolation kit (MO BIO Laboratories, Carlsbad, CA) was utilized to extract community genomic DNA from digestate samples, and a NanoDrop ${ }^{\mathrm{TM}}$ Lite spectrophotometer (Thermo Fisher Scientific Inc., Waltham, MA) was applied to quantify the DNA extraction. Polymerase Chain Reactions (PCR) were conducted to amplify the bacterial $16 \mathrm{~S}$ rRNA gene sequences using a forward primer 357F (5'-CCTACGGGAGGCAGCAG-3') and a reverse primer 926R (5'-CCGTCAATTCMTTTRAGT-3') which targeted on the hypervariable V3-V5 region of rRNA genes [21-23]. A 454 "A" adapter and unique barcode sequences were incorporated in the reverse primer, and a " $\mathrm{B}$ " adapter was incorporated in the forward primer. A $15 \mu \mathrm{L}$ reaction solution contained $0.33 \mu \mathrm{M}$ primer, $0.125 \mathrm{U} \mu \mathrm{L}^{-1}$ high fidelity Taq polymerase (Life Technologies ${ }^{\mathrm{TM}}$, Grand Island, NY), 1X Taq reaction buffer, $0.2 \mathrm{mM}$ of each dNTP, $2 \mathrm{mM} \mathrm{MgSO}_{4}, 0.1 \mathrm{mg} \mathrm{mL}^{-1} \mathrm{BSA}$, and $10 \mathrm{ng}$ DNA template. The reaction solution was mixed with DNase and RNase free water for PCR reaction. The amplification included an initial denaturing step at $95{ }^{\circ} \mathrm{C}$ for $5 \mathrm{~min}$, followed by 30 cycles of 3 temperature steps (denaturing at $95{ }^{\circ} \mathrm{C}$ for $45 \mathrm{~s}$, annealing at $50{ }^{\circ} \mathrm{C}$ for $45 \mathrm{~s}$, and elongation at $72{ }^{\circ} \mathrm{C}$ for $90 \mathrm{~s}$ ), and a final extension at $72{ }^{\circ} \mathrm{C}$ for $5 \mathrm{~min}$. The PCR products were purified using QiaQuick PCR Product Purification kit (Qiagen, Valencia, CA). Purified amplicons were diluted to $0.5 \mathrm{ng}$ dsDNA $\mu \mathrm{L}^{-1}$ and sequenced using a Roche 454 GSFLX Titanium Sequencer at the Research Technology Support Facility of Michigan State University. All bacterial 16S rRNA amplicon sequences were trimmed, screened and analyzed using Ribosomal Database Project (RDP) Pyrosequencing Pipeline Initial Process tools with a minimum sequence length of $300 \mathrm{bp}$ and no ambiguous bases [24]. Chimeras were identified using USEARCH implemented UCHIME algorithm in reference mode with Silva Gold Alignment database [25]. Sequences were assigned with genus names at $80 \%$ confidence level by RDP Multi-Classifier and clustered at $97 \%$ similarity by Complete Linkage Clustering [13].

\subsection{Archaeal community analysis}

DNA extracts from the previous step were also used for archaeal community analysis. The archaeal communities were examined using 16S rRNA gene-based Terminal Restriction Fragment Length Polymorphism (T-RFLP). The 16S rRNA gene was amplified with archaeal domain-specific primers 344 aF-FAM (FAM-5'CGGGGYGCASCAGGCGCGAA- $\left.3^{\prime}\right)$ and 1119aR (5'- 
GGYRSGGGTCTCGCTCGTT-3') [13,26]. A $100 \mu \mathrm{L}$ reaction solution containing 20-40 ng DNA template, $90 \mu$ L Platinum ${ }^{\circledR}$ PCR SuperMix (Invitrogen, Life Technologies Corporation, Carlsbad, CA), $0.25 \mu \mathrm{M}$ primer, and $0.1 \mathrm{mg} \mathrm{mL}^{-1}$ bovine serum albumin (BSA) was prepared for PCR reaction. The amplification included an initial denaturing step at $94{ }^{\circ} \mathrm{C}$ for $5 \mathrm{~min}$, followed by 25 cycles of 3 temperature steps (denaturing at $94^{\circ} \mathrm{C}$ for $1 \mathrm{~min}$, annealing at $50^{\circ} \mathrm{C}$ for $45 \mathrm{~s}$, and elongation at $71^{\circ} \mathrm{C}$ for $100 \mathrm{~s}$ ), and a final extension at $72{ }^{\circ} \mathrm{C}$ for $5 \mathrm{~min}$. The PCR products were then purified using QiaQuick PCR Product Purification kit (Qiagen, Valencia, CA). The purified PCR products were subjected to restriction enzyme digestion with MspI (New England Biolabs Inc., Ipswich, MA). A $15 \mathrm{~mL}$ digestion mixture contained 300-400 ng of purified PCR product, $1.5 \mu \mathrm{L} 10 \mathrm{X}$ enzyme buffer, $0.5 \mu \mathrm{L}$ enzyme $\left(20 \mathrm{U} \mu \mathrm{L}^{-1}\right)$, and $0.1 \mathrm{mg} \mathrm{mL}^{-1} \mathrm{BSA}$. The digestion mixture was incubated at $37^{\circ} \mathrm{C}$ for $3 \mathrm{~h}$ and deactivated at $65^{\circ} \mathrm{C}$ for $10 \mathrm{~min}$. The digested DNA samples $(7 \mu \mathrm{L})$ were analyzed at the Research Technology Support Facility at Michigan State University.

In order to construct archaeal clone libraries, the 16S rRNA genes of four representative samples were amplified with archaea domain-specific primers of $344 \mathrm{aF}$ and 1119aR. Unlike the forward primer 344 aF-FAM used in previous T-RFLP experiment, $344 \mathrm{aF}$ does not contain any fluorescent label (FAM). TOPO TA cloning kit (Invitrogen, Life Technologies Corporation, Carlsbad, CA) with One Shot ${ }^{\mathbb{B}}$ TOP10 Chemically Competent Escherichia coli was used for cloning. A total of 192 clones were picked and screened for each sample, and 96 clones with correct inserts were sequenced at the Research Technology Support Facility of Michigan State University.

Archaeal 16S rRNA gene sequences obtained from clone libraries were processed using RDP. Phylogenetic affiliations were analyzed using the RDP Classifier at an $80 \%$ confidence threshold at genus level.

\subsection{Statistical analysis}

Two-way analysis of variance (ANOVA) and pair-wise comparison using Statistical Analysis System program 9.0 (SAS Institute Inc., Cary, NC) were conducted on biogas production, TS reduction, and $\mathrm{AD}$ fiber composition to compare the $\mathrm{AD}$ characteristics and performance among six experimental treatments.

Statistical software $\mathrm{R}$ with package Vegan was used to perform the operational taxonomic unit (OTU)- and phylotype-based analyses of both bacterial and archaeal communities. Specifically, nonmetric multidimensional scaling analysis (NMDS) was used to correlate the dissimilarities between samples and the variations in phylotype abundance. The $\mathrm{R}$ package Vegan was also applied to estimate the diversity index (Shannon's $H$ ), community evenness (Pielou's $J$ ) and rarefaction curve for each sample based on clustered sequences. The sampling coverage $(\mathbf{C})$ of each bacterial sample was calculated based on Good's method, $\mathbf{C}=1-\mathrm{n}_{1} / N$, where $\mathrm{n}_{1}$ represents number of OTUs, and $N$ is the total number of sequences in the sample [27].

Peak Scanner ${ }^{\mathrm{TM}}$ Software v1.0 (Applied Biosystems ${ }^{\circledR}$, Life Technologies Corporation, Carlsbad, CA) was applied to perform DNA fragment analysis. Peaks below 50 fluorescence units were filtered out to eliminate the background noise. Comparisons of T-RFLP results among samples were conducted by T-Align [28].

\section{Results and discussion}

\subsection{Characteristics of feedstocks}

Table 1 presents the characteristics of dairy manure and food waste, which includes total carbon (C), total nitrogen $(\mathrm{N})$, free sugars and starch, structural carbohydrates (cellulose and xylan), as well as lignin. It is noticeable that even though food waste contained a similar amount of total carbon (47.8\%) with dairy manure (43.7\%), it had significantly more available carbon $(\mathrm{p}=0.001)$ but less cellulose $(p=0.05)$ and xylan $(p=0.007)$. This is due to the difference in diets between ruminant and human: dairy cows were fed on alfalfa and corn silage, both of which are fibrous lignocelluloses; while food waste from the university cafeterias contained less fiber but more free sugars and starch (Table 1). In addition, high total nitrogen content in food waste also attributes to human's high protein diet (meat and dairy). $\mathrm{C} / \mathrm{N}$ ratio in the organic material plays a crucial role in the anaerobic digestion. A high $\mathrm{C} / \mathrm{N}$ ratio indicates a rapid consumption of nitrogen by the microbes, which could result in a reduction of biogas productivity [29]. While, a lower $\mathrm{C} / \mathrm{N}$ ratio leads to carbon deficiency, ammonia accumulation and pH increase, all of which inhibit reproduction and metabolism of the methanogens $[30,31]$. Therefore, mixing food waste with dairy manure could provide a balanced $\mathrm{C} / \mathrm{N}$ for a healthy and efficient $\mathrm{AD}$ process [32-34].

\subsection{Effects of feedstock composition and culture temperature on digestion performance}

Fig. 1 and Table 2 illustrate the performance of digesters under six different conditions. In general, methane content in biogas ranged from 58.3 to $67.6 \%$ without significant difference among all experimental runs $(\mathrm{p}=0.117)$. Daily biogas production and carbon removed from the feed were significantly correlated to supplemental food waste ( $p=0.001$ and 0.004 , respectively) and reaction temperature ( $\mathrm{p}=0.001$ and 0.005 , respectively). The interactions between these two factors also had significant impacts ( $p=0.001$ and 0.041 , respectively) on the daily biogas production and carbon removal from the feed. With the increase of the food waste percentage, both mean biogas production and carbon removal were significantly improved. On the contrary, fiber analysis demonstrates that neither reaction temperature nor supplemental food waste had impacts on cellulose $(\mathrm{p}=0.632$ and 0.522 , respectively), xylan ( $\mathrm{p}=0.478$ and 0.253 , respectively), and lignin ( $\mathrm{p}=0.998$ and 0.165 , respectively) contents in the solid digestate. In other words, this study demonstrates that within a certain range of variation in feedstock composition (mainly controlled by available $\mathrm{C} / \mathrm{N}$ ratio), AD system could adjust itself in order to maximize carbon utilization for biogas production and generate homogenized solid digestate with similar carbohydrate content. Considering the potential application of solid digestate as a feedstock for biorefining of biofuel and chemical production [14-18], the AD function of homogenizing carbohydrate components in the solid digestate from different feeds might provide a solution to address the compositional diversity the issue of different lignocellulosic feedstock that lignocellulosic biorefining processes encounter.

In order to further evaluate the $\mathrm{AD}$ performance between different combination of temperature and feed ratio, daily biogas productivity was introduced to conduct the comparison. The daily biogas productivity [mL $\mathrm{g}^{-1}$ TS reduction $\mathrm{L}^{-1}$ digestion] was calculated by dividing the daily biogas accumulation $\left[\mathrm{mL} \mathrm{L}^{-1}\right.$ digestion day $^{-1}$ ] by daily TS reduction [ $g$ TS reduction day ${ }^{-1}$ ]. The biogas productivity data present that within the boundary of the experimental conditions temperature had no significant influence $(\mathrm{p}=0.206)$ on biogas production (Fig. 2). While, increasing the percentage of food waste in the feed significantly increased the biogas productivity $(\mathrm{p}=0.002)$. It is apparent that easyhydrolyzing carbon sources of free sugars and starch in food waste enhanced the $\mathrm{AD}$ performance to produce biogas, homogenized fiber quality of the solid digestate. 
Table 1

Characteristics of feedstock ${ }^{\mathrm{a}}$.

\begin{tabular}{|c|c|c|c|}
\hline & Dairy manure & Food waste & Comparison \\
\hline Total carbon (wt\%, dry basis) & 43.7 & 47.8 & $\mathrm{p}=0.061$ \\
\hline Total available carbon (wt\%, dry basis) & 24.8 & 39.9 & $\mathrm{p}=0.001$ \\
\hline Free sugars and starch (wt\%, dry basis) & Not detectable & 34.6 & $\mathrm{p}<0.001$ \\
\hline Cellulose (wt\%, dry basis) & 22.7 & 16.5 & $\mathrm{p}=0.005$ \\
\hline Xylan (wt\%, dry basis) & 13.9 & 4.9 & $\mathrm{p}=0.007$ \\
\hline Lignin (wt\%, dry basis) & 28.4 & 11.9 & $\mathrm{p}=0.009$ \\
\hline Total nitrogen (wt\%, dry basis) & 2.1 & 5.3 & $\mathrm{p}=0.005$ \\
\hline $\mathrm{C}: \mathrm{N}$ ratio, total $\mathrm{C}$ & 20.6 & 9.0 & - \\
\hline $\mathrm{C}: \mathrm{N}$ ratio, available $\mathrm{C}^{\mathrm{b}}$ & 11.8 & 7.5 & - \\
\hline
\end{tabular}

${ }^{a}$ Data listed represent the average of two biological replicates.

b Available carbon excludes organic matters (i.e. lignin) that are not able to be utilized by anaerobic microbes.

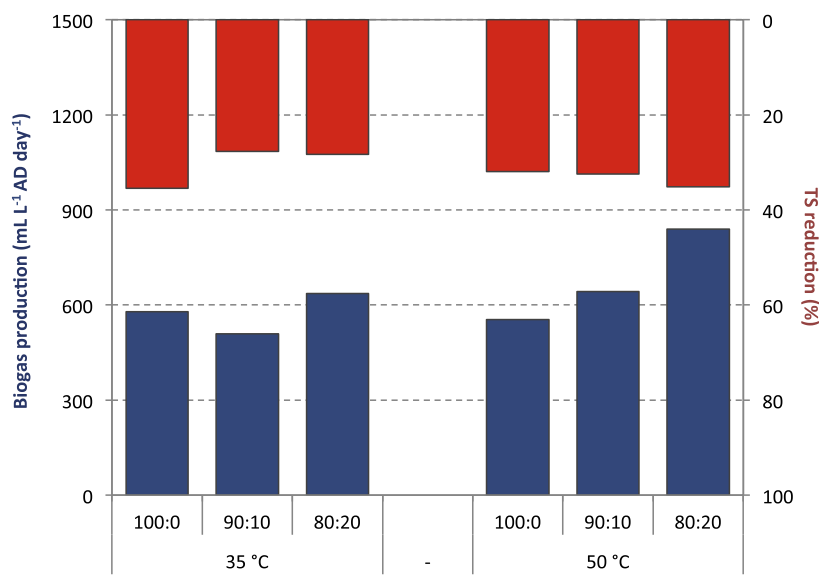

Fig. 1. Effects of feedstock composition and culture temperature on digestion performance. Top bars with red color are TS reduction, bottom bars with blue color are biogas production. Data are average of two replicates. (For interpretation of the references to colour in this figure legend, the reader is referred to the web version of this article.)

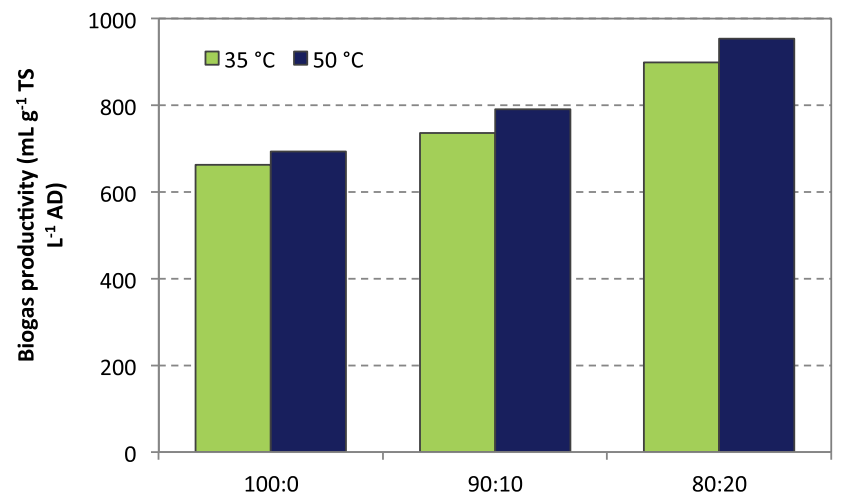

Fig. 2. Daily biogas productivity (daily biogas accumulation vs TS reduction). Daily biogas productivity is calculated using daily biogas accumulation divided by TS reduction. Data are average of two replicates.

Table 2

Performance of anaerobic digestion ${ }^{\mathrm{a}}$

\begin{tabular}{|c|c|c|c|c|c|c|c|}
\hline & & Daily biogas ( $\left.\mathrm{mL} \mathrm{L}^{-1} \mathrm{AD} \mathrm{day}^{-1}\right)$ & $\mathrm{CH}_{4}(\%)$ & Carbon removal from the feed ${ }^{\mathrm{b}}(\%)$ & Cellulose in residue (\%) & Xylan in residue (\%) & Lignin in residue (\%) \\
\hline \multirow[t]{3}{*}{$35^{\circ} \mathrm{C}$} & $100 / 0$ & 558.9 & 58.3 & 27.4 & 23.1 & 14.3 & 36.4 \\
\hline & $90 / 10$ & 499.1 & 65.2 & 24.2 & 22.3 & 13.5 & 36.4 \\
\hline & $80 / 20$ & 626.5 & 60.1 & 30.2 & 23.9 & 13.6 & 34.4 \\
\hline \multirow[t]{3}{*}{$50^{\circ} \mathrm{C}$} & $100 / 0$ & 554.4 & 59.0 & 27.2 & 25.3 & 14.8 & 38.0 \\
\hline & $90 / 10$ & 642.1 & 58.6 & 31.2 & 22.4 & 13.8 & 35.0 \\
\hline & $80 / 20$ & 848.8 & 67.6 & 40.9 & 23.4 & 13.7 & 34.3 \\
\hline
\end{tabular}

a Data listed represent the average of two biological replicates.

b Carbon removed from the feed means that the percentage of carbon in the feed has been consumed for biogas production.

\subsection{Effects of feedstock composition and culture temperature on anaerobic microbes}

The afore mentioned performance results demonstrate that AD can efficiently adjust itself to adapt into different nutrient conditions to maintain the performance of digestion. Considering that anaerobic microbes are the powerhouse of $\mathrm{AD}$, the relationship between microbial communities, digestion conditions, biogas production, and digestate composition should be delineated in order to better understand microbial responses to digestion conditions, and enable engineering of anaerobic microbial communities to fulfill both biogas production and lignocellulose pretreatment. Metagenomic analysis was carried on to elucidate such relationship. The bacterial and archaeal communities were separately discussed in this section.

\subsubsection{Anaerobic bacterial community}

The pyrosequencing results demonstrate that the total bacterial 16S rRNA gene sequences in a sample ranged from 1594 to 30,295 among 12 digestate samples (Table 3 ). Although rarefaction curves (Fig. S1) demonstrate a great unsampled diversity across all 12 digesters, especially in those who had fewer sequences, the Good's coverage (C) ranged from $89.0 \%$ to $98.8 \%$ with an average of $94.5 \%$. Allers et al. [35] used Good's numbers to indicate the diversity of an environmental microbial community and they found that most of the gammaproteobacteria were covered with the Good's numbers fell between $70 \%$ and $80 \%$. Therefore, the Good's numbers from all 12 AD samples indicated a high sampling coverage of bacterial community.

Based on bacterial 16S rRNA gene targeted sequencing, bacterial diversities $\left(H_{\text {bact }}\right)$ of mesophilic digesters were significantly higher 
Table 3

The diversity and evenness of bacterial and archaeal communities calculated based on their 16S rRNA gene targeted sequencing.

\begin{tabular}{|c|c|c|c|c|c|c|c|c|c|}
\hline \multirow[t]{2}{*}{ Temp } & \multirow[t]{2}{*}{ Ratio } & \multirow[t]{2}{*}{ ID } & \multicolumn{5}{|c|}{ Bacteria } & \multicolumn{2}{|c|}{ Archaea } \\
\hline & & & $N_{\text {bact }}{ }^{\mathrm{a}}$ & OTU $_{\text {obs }}{ }^{\mathrm{b}}$ & $\mathbf{C}(\%)^{\mathrm{c}}$ & $\mathrm{H}_{\text {bact }}{ }^{\mathrm{d}}$ & $J_{\text {bact }}{ }^{\mathrm{e}}$ & $\mathrm{H}_{\text {arch }}{ }^{\mathrm{d}}$ & $J_{\text {arch }^{\mathrm{e}}}$ \\
\hline \multirow[t]{6}{*}{$35^{\circ} \mathrm{C}$} & \multirow[t]{2}{*}{$100: 0$} & MI1 & 30,295 & 368 & 98.79 & 2.67 & 0.55 & 1.67 & 0.80 \\
\hline & & MI2 & 13,987 & 227 & 98.38 & 2.78 & 0.59 & 1.85 & 0.77 \\
\hline & \multirow[t]{2}{*}{$90: 10$} & MI3 & 13,589 & 224 & 98.35 & 3.08 & 0.64 & 2.06 & 0.83 \\
\hline & & MI4 & 3492 & 282 & 91.92 & 3.07 & 0.71 & 1.98 & 0.77 \\
\hline & \multirow[t]{2}{*}{$80: 20$} & MI5 & 4126 & 277 & 93.29 & 3.25 & 0.73 & 1.84 & 0.77 \\
\hline & & MI6 & 4116 & 301 & 92.69 & 3.46 & 0.75 & 1.74 & 0.76 \\
\hline \multirow[t]{6}{*}{$50^{\circ} \mathrm{C}$} & \multirow[t]{2}{*}{ 100:0 } & MI7 & 3770 & 328 & 91.30 & 2.52 & 0.58 & 1.80 & 0.72 \\
\hline & & MI8 & 10,416 & 220 & 97.89 & 2.73 & 0.58 & 1.52 & 0.85 \\
\hline & \multirow[t]{2}{*}{$90: 10$} & MI9 & 10,849 & 213 & 98.04 & 2.23 & 0.43 & 1.59 & 0.82 \\
\hline & & MI10 & 1594 & 176 & 88.96 & 2.81 & 0.66 & 1.66 & 0.80 \\
\hline & \multirow[t]{2}{*}{$80: 20$} & MI11 & 2988 & 247 & 91.73 & 2.65 & 0.62 & 1.63 & 0.84 \\
\hline & & MI12 & 2689 & 204 & 92.41 & 2.62 & 0.59 & 1.60 & 0.82 \\
\hline
\end{tabular}

a $N_{\text {bact }}$ is the total bacterial $16 \mathrm{~S}$ rRNA gene sequences in the sample.

b OTU $_{\text {obs }}$ is the number of observed OTUs for an OTU definition.

c $\mathbf{C}$ is the sample/Good's coverage for an OTU definition.

${ }^{\mathrm{d}} H$ is the Shannon's index which indicates the diversity of the microbial community; the subscript bact represents bacteria and arch represents archaea.

e $J$ is the Pielou's index which indicates the evenness of the microbial community; the subscript bact represents bacteria and arch represents archaea.

than thermophilic digesters $(\mathrm{p}=0.006)$. Several previous studies on anaerobic digestive microbial community also revealed similar trend [36-38], which could be the reason why mesophilic AD is more robust to environmental changes than thermophilic process. However, the Pielou's evenness ( $J_{\text {bact }}$ ) indices did not show any significant difference among treatments ( $p \geq 0.084$ ), which means that different bacterial communities had similar variations between OTUs. In addition, a combined dendrogram and heat map was generated to demonstrate the similarity of bacterial communities across all samples (Fig. 3a). From the top of the dendrogram (left-side of the figure), the first separation of clades shows a community shift caused by reaction temperature. The cluster with samples MI7-MI12 is thermophilic digesters $\left(50{ }^{\circ} \mathrm{C}\right)$ and the one with samples MI1-MI6 is mesophilic digesters $\left(35^{\circ} \mathrm{C}\right)$. At both temperatures, the digesters fed on dairy manure only (MI1\&2 at $35^{\circ} \mathrm{C}$, and MI7\&8 at $50{ }^{\circ} \mathrm{C}$ ) were significantly differentiated from the ones fed on the mixture feed with $80: 20$ ratio (MI5\&6 at $35^{\circ} \mathrm{C}$, and MI11\&12 at $50{ }^{\circ} \mathrm{C}$ ). Meanwhile, the bacterial communities in 90: 10 digesters ( $\mathrm{MI} 3 \& 4$ at $35^{\circ} \mathrm{C}$, and MI9\&10 at $50{ }^{\circ} \mathrm{C}$ ) behaved like an intermediate state between the other two feed ratios, and their replicates illustrated closeness to either $100 \%$ dairy manure or $80: 20$ ratio digesters. This result indicates that bacterial community of an AD system gradually shifted its structure with the change of the feedstock. Yue et al. [13] also observed a bacterial community shift by supplementing corn stover into a dairy manure AD system. A heat map of the most abundant bacterial genera in 12 samples (Fig. 3a) demonstrates a higher microbial density and diversity in mesophilic digesters (MI1-6). Moreover, digesters had higher manure in the feedstock generally had higher microbial density.

Ribosomal Database Project's Multi-Classifier with a minimal bootstrap value of 80 was used to determine the bacterial taxa. A total of 23 phyla were assigned and overall $8.6 \%$ of total sequence was categorized as unclassified bacteria. At genus level, a total of 363 bacterial groups (275 classified and 88 unclassified) were identified. Bacteroidetes (46-69\% at $35{ }^{\circ} \mathrm{C}, 16-28 \%$ at $50{ }^{\circ} \mathrm{C}$ ), Firmicutes $\left(20-45 \%\right.$ at $35^{\circ} \mathrm{C}, 45-62 \%$ at $\left.50{ }^{\circ} \mathrm{C}\right)$, Proteobacteria $(2-5 \%$ at $35{ }^{\circ} \mathrm{C}, 4-7 \%$ at $\left.50{ }^{\circ} \mathrm{C}\right)$ and Spirochaetes $\left(1-8 \%\right.$ at $\left.35{ }^{\circ} \mathrm{C}\right)$ were the most abundant phyla in all 6 treatments (12 digesters) (Fig. 4a). In addition, Thermotogae (18\%) was only observed in thermophilic digesters with the 80:20 ratio. Synergistetes (1-2\%) in mesophilic digesters and Chloroflexi (8-14\%) in thermophilic digesters were also major components of their microbial communities (Fig. 4a, wide columns). Within these phyla, Clostridia $\left(19-41 \%\right.$ at $35{ }^{\circ} \mathrm{C}$, $44-61 \%$ at $50{ }^{\circ} \mathrm{C}$ ), unclassified Bacteroidetes (30-38\% at $35^{\circ} \mathrm{C}, 2-4 \%$ at $\left.50{ }^{\circ} \mathrm{C}\right)$, Petrimonas $\left(4-7 \%\right.$ at $35^{\circ} \mathrm{C}, 6-8 \%$ at $\left.50{ }^{\circ} \mathrm{C}\right)$ and Bacteroides ( $1 \%$ at $35{ }^{\circ} \mathrm{C}, 1-2 \%$ at $50{ }^{\circ} \mathrm{C}$ ) were highly abundant (Fig. 4 a, thin columns). Thermophilic digesters tended to accumulate more Firmicutes while mesophilic ones had significantly more Bacteroidetes. Class Clostridia comprised 91-98\% of the phylum Firmicutes across 6 runs (12 digesters). Within phylum Bacteroidetes, unclassified Bacteroidetes was a significant component $(\mathrm{p}<0.001)$ in mesophilic digesters. In addition, the fractions of Petrimonas in all 6 runs were similar (5-8\%), but total amount of Bacteroides in the AD treatments was significantly lower than that in original dairy manure.

Phylum Bacteroidetes as one of the major bacterial groups in $\mathrm{AD}$ include several strains such as Flavobacterium johnsoniae, Sporocytophaga myxococcoides, and Cytophaga sp. that have been repeatedly reported as degraders of structural carbohydrates of plants [39-41]. A recent study on bacterial community in anaerobic digesters [13] also showed that unclassified Bacteroidetes was one of dominant taxa in lignocellulose-rich co-digestion systems. Besides cellulose/hemicellulose degradation, it has also been reported that many members of Bacteroidetes are proteolytic bacteria which can degrade protein and convert amino acids to acetate $[43,44]$.

Class Clostridia was another major bacterial group in anaerobic digestion. As saprophytic bacteria, they commonly show high cellulolytic activity as well as capability of degrading volatile fatty acids such as butyrate and its analog compounds [43,45]. Moreover, some strains of Clostridia can also utilize cellobiose and glucose generated from carbohydrate degradation to produce proton and hydrogen gas.

Chlorflexi, Synergistetes, Spirochaetes and Thermotogae are other phyla that have been detected in the digesters. It has been reported that Chloroflexi have potential to treat wastes in anaerobic environment, such as thriving in naturally anaerobic dechlorination [46], wastewater treatment processes [47], and degrading carbohydrates $[43,48]$. Synergistetes are able to consume amino acids and produce short chain fatty acids as well as sulphate for methanogenic archaea and sulphate-reducing bacteria [49]. They prefer mesophilic environment [50] as shown in this study. Spirochaetes can break down cellulose and other plant polysaccharides, and their optimum living temperature is also mesophilic [51]. Noticeably, Thermotogae only appeared in thermophilic digesters with 80:20 ratio that had the highest biogas productivity among all treatments, which may be related to their capability of degrading different complex-carbohydrates and producing acetic acid, carbon dioxide and hydrogen gas [52].

Non-metric multidimentional scaling (NMDS) analysis was performed based on the complete linkage clustering of 16S rRNA gene sequences of all 12 digesters (6 treatments with duplicates) (Fig. 5a). The differences of bacterial communities between two reaction temperatures were significant $(p=0.001)$, though, the supplemental food waste did not have significant impact on the community shift $(\mathrm{p}=0.148)$. The biogas productivities were significantly different among treatments $(\mathrm{p}=0.012)$, and the direction of its arrow indicates that digesters with 80:20 feed ratio had the highest biogas productivity (Fig. 5a). Similarly, the arrow of TS reduction shows an improved performance trend with elevated temperature and no-supplemental food wastes, even though the difference was not significant $(p=0.453)$. Fitting the dominant bacetrial taxa to the community distances reveals that phyla Bacteroidetes $(\mathrm{p}<0.001)$, Synergistetes $(\mathrm{p}=0.038)$ and Spirochaetes $(\mathrm{p}=0.028)$ preferred mesophilic AD condition, while phyla Chloroflexi $(\mathrm{p}<0.001)$, Thermotogae $(\mathrm{p}=0.019)$ and Firmicutes $(\mathrm{p}=0.004)$ tended to accumulate more at thermophilic condition $\left(50{ }^{\circ} \mathrm{C}\right)$. In addition, Firmicutes $(\mathrm{p}=0.035)$ preferred the increased 

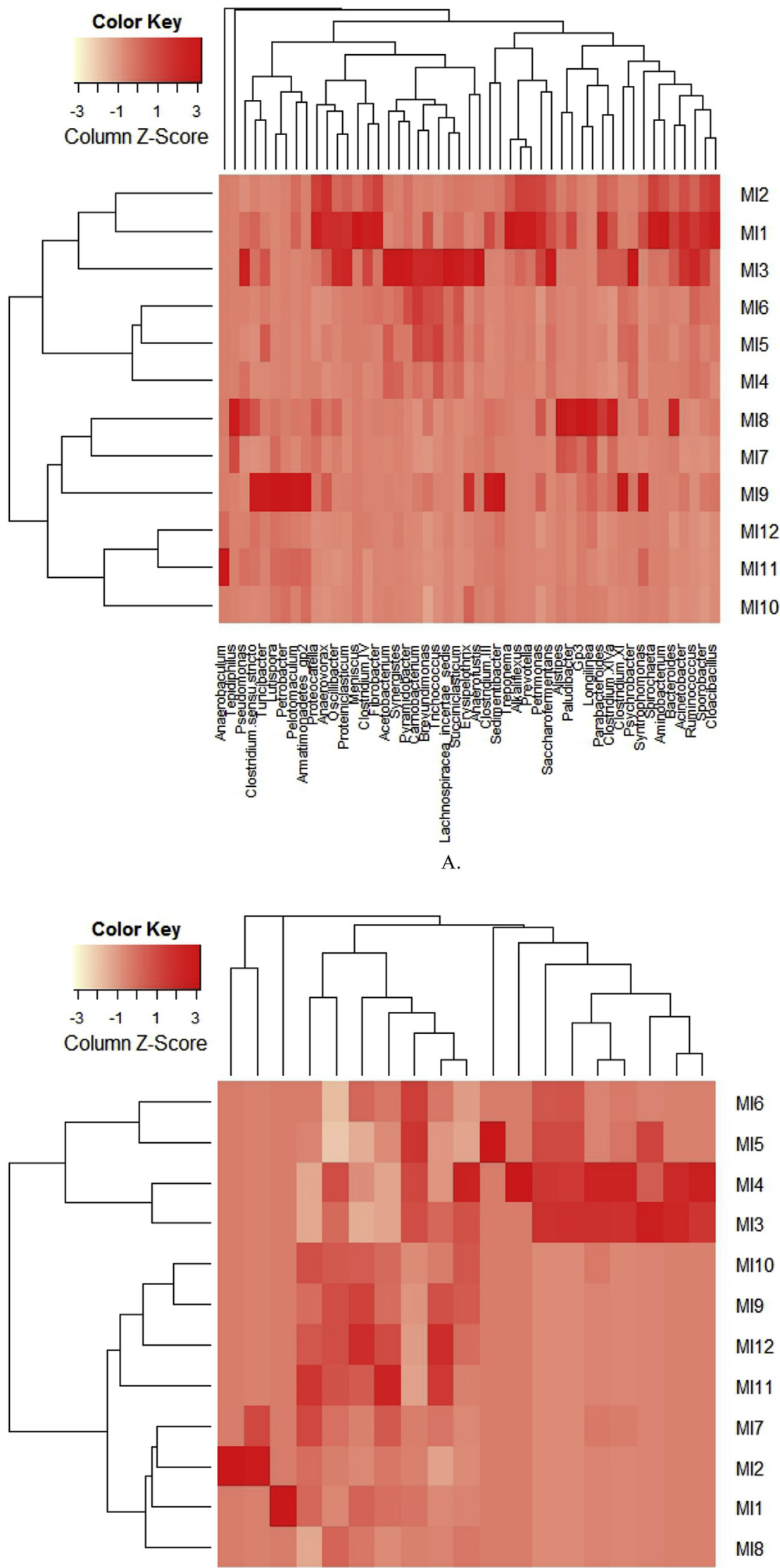

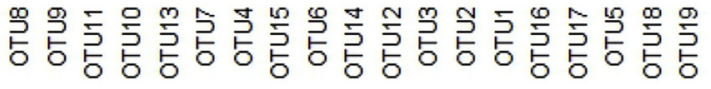
B

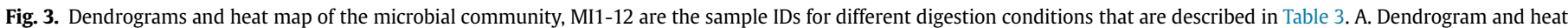
map of bacterial community (based on the most common genera from 454 pyrosequencing). B. Dendrogram and heat map of archaeal community (based on T-RFLP results). 

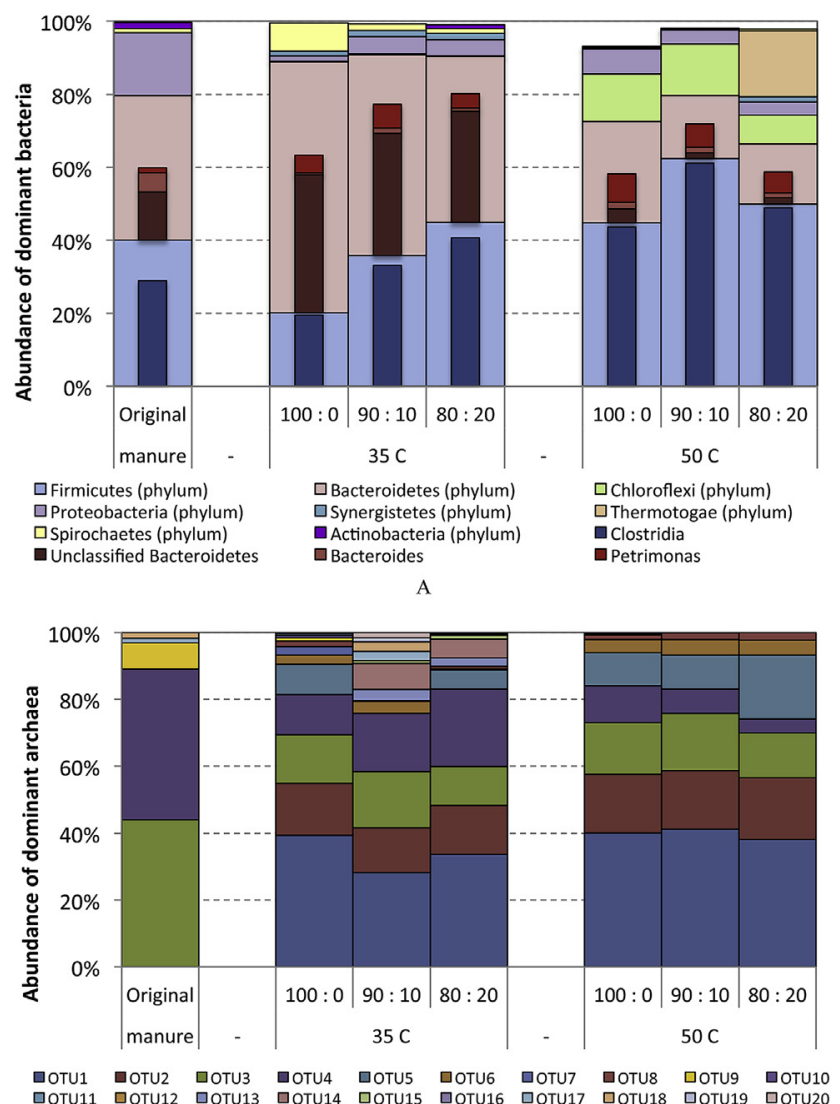

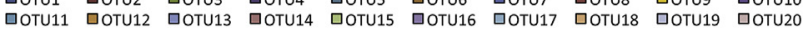

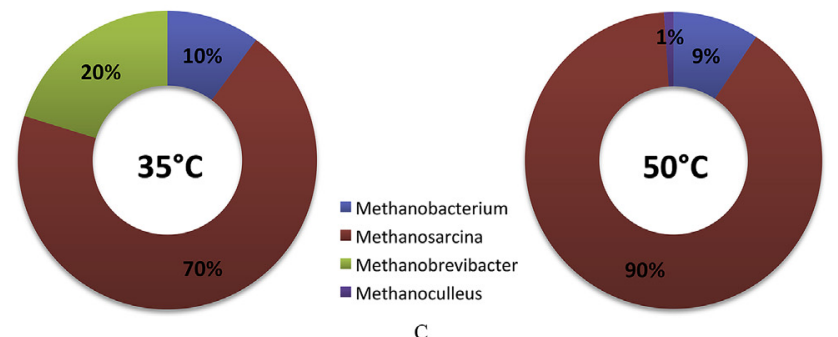

$\mathrm{C}$

Fig. 4. Abundance of bacterial and archaeal communities. A. Assembly of dominant bacteria (wide columns indicate dominant bacterial phyla and thin columns indicate dominant bacterial classes). B. Distribution of dominant archaea under different culture conditions (based on T-RFLP results). C. Main archaea from the digestions under different temperatures (based on clone library).

amount of supplemental food waste, while Bacteroidetes ( $p=0.003$ ) had higher abundance in $100 \%$ dairy manure digesters. Although both phyla Firmicutes (especially class Clostridia) and Bacteroidetes were reported to be able to degrade crystalline fiber into organic acids $[13,53,54]$, Sundberg et al. [55] reported that Bacteroidetes were more susceptible to the environmental change caused by additional food waste, such as ammonia accumulation and $\mathrm{pH}$ fluctuation. The correlation between $\mathrm{AD}$ performance and bacterial community change also becomes obvious on this NMDS diagram. Bacterial communities tended to adapt themselves into different culture conditions and maximize their capability to convert all available carbon sources (free sugar, starch, protein, fat, hemicellulose, and easy-degradable cellulose) into biogas (Fig. 1 and Table 2). As a result, differences in compositional cellulose $(\mathrm{p}=0.626)$, xylan $(\mathrm{p}=0.128)$ and lignin $(\mathrm{p}=0.113)$ of the solid digestates among all six treatments were not significant, which means the bacterial metabolism reached an equilibrium for each treatment and relatively homogenized carbohydrate composition in the solid digestate.

\subsubsection{Anaerobic archaeal community}

The Shannon's diversity indices of archaea $\left(H_{\text {arch }}\right)$ calculated from the aligned and clustered $(0.03 \%$ cutoff $)$ sequences were relatively low (Table 3), which indicated a low diversity within archaeal communities of all treatments. The Pielou's evenness indices (Jarch) of archaea also show that archaeal communities had less variation. In Fig. 3b, the archaeal dendrogram demonstrates community similarity across all treatments, and the heat map presents that several archaeal OTUs had higher density within mesophilic digesters. When temperature increased, archaea in the co-digestion systems also shifted accordingly, though, the ones in $100 \%$ manure digesters were relatively consistent regardless of temperature change. Statistically, reaction temperature $(p=0.001)$ had significant impacts on the change of archaeal community while the amount of supplemental food waste did not $(\mathrm{p}=0.441)$. The community abundance of archaea based on T-RFLP test (Fig. 4b) shows a relatively uniform assembly across all treatments. However, they were all significantly different from the archaea community in the original dairy manure. Moreover, similar to bacteria, archaeal communities in mesophilic digesters were more diverse than thermophilic digesters. Further phylogenetic affiliations based on clone library illustrated four genera of methanogenic archaea were detected in the digesters (Fig. 4c). In details, the abundance of Methanosarcina increased from $70 \%$ to $90 \%$ when reaction temperature was raised from $35{ }^{\circ} \mathrm{C}$ to $50{ }^{\circ} \mathrm{C}$, while Methanobrevibacter reduced from 20\% to nondetectable. Results also demonstrate a higher hydrogentrophic methanogen assembly (i.e. Methanobrevibacter, Methanobacterium and Methanoculleus) in mesophilic digeseters. The abundance change of Methanobrevibacter due to temperature was expected since the optimum temperature for both genera was $37-38^{\circ} \mathrm{C}$ [56,57]. Methanocarsina is a genus that uses aceticlastic pathway to generate methane [13]; therefore, its dominance in the clone libraries illustrates that aceticlastic reactions of methanogensis were the dominant route to methane in all digesters.

The NMDS analysis of archaeal community (Fig. 5b) shows the methane content in biogas was similar among all treatments $(p=0.117)$. The direction of the arrow illustrates that digesters at $35{ }^{\circ} \mathrm{C}$ had relatively higher methane content. Similar observation was reported previously [58-60]. The biogas productivities and TS reduction were discussed in previous bacterial NMDS section. Fitting the dominant archaeal genera to the community distances demonstrated that increasing the reaction temperature had significant impact on Methanosarcina ( $\mathrm{p}=0.001)$ positively, but negatively on Methanobrevibacter $(\mathrm{p}=0.031)$.

\section{Conclusion}

A variety of molecular and statistical approaches were applied to examine the responses of microbial communities to the changes of digestion conditions and their impacts on biogas production and solid digestate quality. The biogas productivity increased significantly with the increase of supplemental food waste. Reaction temperature did not show any significant effect on biogas production within the experimental conditions. There were no significant differences on carbohydrate contents of solid digestate among six treatments. The alikeness of methane content among all six treatments and the analysis of archaea community both proved that methanogens were lack of diversity and they only varied with reaction temperature. Analysis of bacterial community revealed that even though each treatment had its distinct bacterial composition, the community changed their 


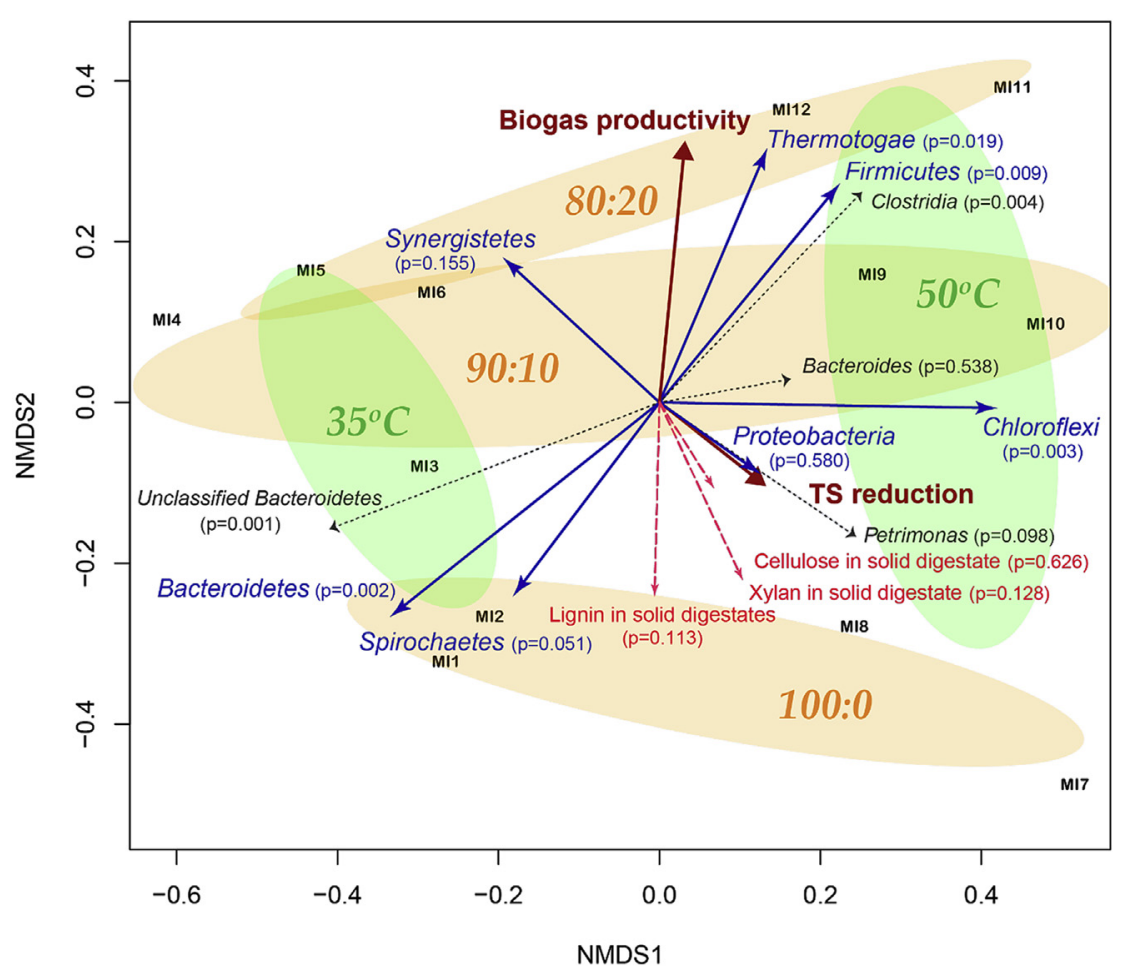

A

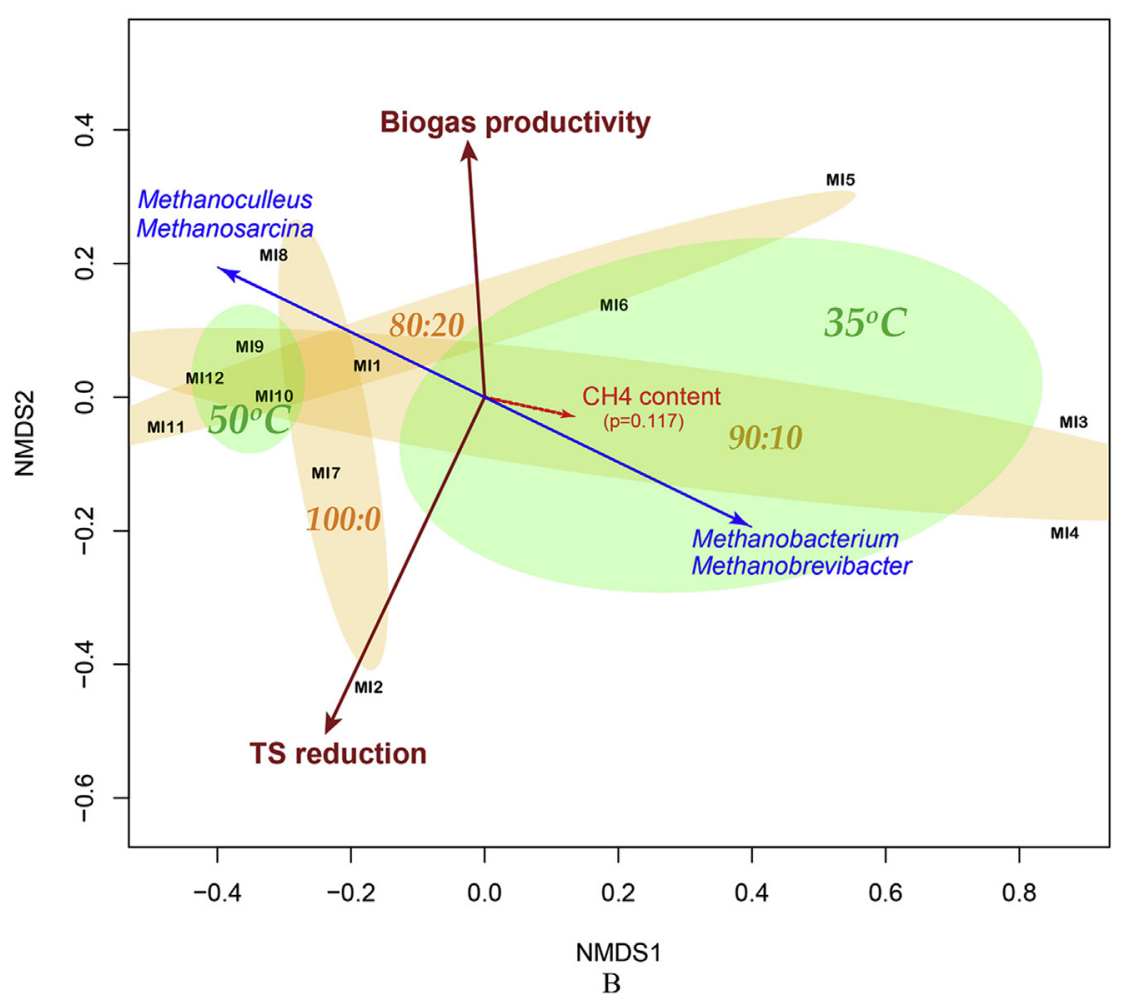

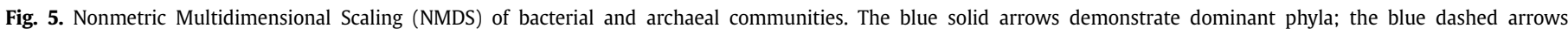

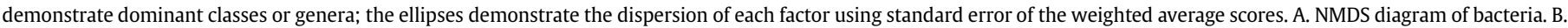
NMDS diagram of archaea. (For interpretation of the references to colour in this figure legend, the reader is referred to the web version of this article.)

configuration to adapt the environment, enhanced the utilization of available carbon for biogas production, and homogenized carbohydrate components in the solid digestate. In-depth studies on the $\mathrm{AD}$ function of homogenizing solid digestate are urgently needed in order to develop an AD-based pretreatment method for lignocellulosic biorefining of biofuel and chemical production. 


\section{Acknowledgment}

This research has been supported by the U.S. Department of State West Hemisphere Affairs (S-LMAQM-11-GR-075). The authors thank the Research Technology Support Facility of Michigan State University for their help on gene sequencing.

\section{Appendix A. Supplementary data}

Supplementary data related to this article can be found at http:// dx.doi.org/10.1016/j.biombioe.2015.11.028.

\section{References}

[1] F. Humenik, J. Martin, M. Rice, K. Roos, Anaerobic Digestion of Animal Manure, 2004. www.epa.gov.

[2] Loehr RC, Agricultural Waste Management: Problems, Processes and Approaches, Academic Press, New York, 1974.

[3] K. Liu, Y.Q. Tang, T. Matsui, S. Morimura, X.L. Wu, K. Kida, Thermophilic anaerobic co-digestion of garbage, screened swine and dairy cattle manure, J. Biosci. Bioeng. 107 (2009) 54.

[4] C.L. Gou, Z.H. Yang, J. Huang, H.L. Wang, H.Y. Xu, L.K. Wang, Effects of temperature and organic loading rate on the performance and microbial community of anaerobic co-digestion of waste activated sludge and food waste, Chemosphere 105 (2014) 146.

[5] J. Mata-Alvarez, J. Dosta, M.S. Romero-Guza, X. Fonoll, M. Peces, S. Astals, A critical review on anaerobic co-digestion achievements between 2010 and 2013, Renew. Sustain. Energy Rev. 36 (2014) 412.

[6] S.I. Safferman, D.M. Kirk, L.L. Faivor, W.-H. Wei, Anaerobic digestion processes, in: R. Mohee, A. Mudhoo (Eds.), Bioremediation and Sustainability : Research and Applications, John Wiley \& Sons, 2012, p. 103.

[7] Y.C. Song, S.J. Kwon, J.H. Woo, Mesophilic and thermophilic temperature cophase anaerobic digestion compared with single-stage mesophilic- and thermophilic digestion of sewage sludge, Water Res. 38 (2004) 1653.

[8] M. Lee, T. Hidaka, W. Hagiwara, H. Tsuno, Comparative performance and microbial diversity of hyperthermophilic and thermophilic co-digestion of kitchen garbage and excess sludge, Bioresour. Technol. 100 (2009) 578.

[9] B. Dearman, P. Marschner, R.H. Bentham, Methane production and microbial community structure in single-stage batch and sequential batch systems anaerobically co-digesting food waste and biosolids, Appl. Microbiol. Biotechnol. 69 (2006) 589.

[10] Y. Zhang, E.M. Zamudio Canas, Z.W. Zhu, J.L. Linville, S. Chen, Q. He, Robustness of archaeal populations in anaerobic co-digestion of dairy and poultry wastes, Bioresour. Technol. 102 (2011) 779.

[11] L. Martin-Gonzalez, R. Castro, M.A. Pereira, M.M. Alves, X. Font, T. Vicent, Thermophilic co-digestion of organic fraction of municipal solid wastes with FOG wastes from a sewage treatment plant: reactor performance and microbial community monitoring, Bioresour. Technol. 102 (2011) 4734.

[12] D. Yu, J.M. Kurola, K. Lahde, M. Kymalainen, A. Sinkkonen, M. Romantschuk, Biogas production and methanogenic archaeal community in mesophilic and thermophilic anaerobic co-digestion processes, J. Environ. Manag. 143 (2014) 54.

[13] Z.B. Yue, R. Chen, F. Yang, J. MacLellan, T. Marsh, Y. Liu, et al., Effects of dairy manure and corn stover co-digestion on anaerobic microbes and corresponding digestion performance, Bioresour. Technol. 128 (2013) 65.

[14] R. Chen, B.D. Thomas, Y. Liu, W. Mulbry, W. Liao, Effects of algal hydrolyzate as reaction medium on enzymatic hydrolysis of lignocelluloses, Biomass Bioenergy 67 (2014) 72.

[15] R. Chen, Z.B. Yue, L. Deitz, Y. Liu, W. Mulbry, W. Liao, Use of an algal hydrolysate to improve enzymatic hydrolysis of lignocellulose, Bioresour. Technol. 108 (2012) 149.

[16] C. Teater, Z.B. Yue, J. MacLellan, Y. Liu, W. Liao, Assessing solid digestate from anaerobic digestion as feedstock for ethanol production, Bioresour. Technol. $102(2011) 1856$.

[17] Z.B. Yue, C. Teater, Y. Liu, J. MacLellan, W. Liao, A sustainable pathway of cellulosic ethanol production integrating anaerobic digestion with biorefining, Biotechnol. Bioeng. 105 (2010) 1031.

[18] Z.B. Yue, C. Teater, J. MacLellan, Y. Liu, W. Liao, Development of a new bioethanol feedstock - Anaerobically digested fiber from confined dairy operations using different digestion configurations, Biomass \& Bioenergy 35 (2011) 1946.

[19] Nutrition SoDC, Nutrition CoA, Council NR, Nutrient Requirements of Dairy Cattle, Seventh Revised Edition, The National Academies Press, 2001.

[20] A. Sluiter, B. Hames, R. Ruiz, C. Scarlata, J. Sluiter, D. Templeton, et al., Determination of Structural Carbohydrates and Lignin in Biomass: Laboratory Analytical Procedure (LAP), National Renewable Energy Laboratory, Golden, CO, USA, 2008.

[21] B.J. Haas, D. Gevers, A.M. Earl, M. Feldgarden, D.V. Ward, G. Giannoukos, et al., Chimeric 16S rRNA sequence formation and detection in Sanger and 454pyrosequenced PCR amplicons, Genome Res. 21 (2011) 494.
[22] B.M. Brinkman, F. Hildebrand, M. Kubica, D. Goosens, J. del Favero W. Declercq, et al., Caspase deficiency alters the murine gut microbiome, Cell Death Dis. (2011) 2

[23] G.A. Preidis, D.M. Saulnier, S.E. Blutt, T.-A. Mistretta, K.P. Riehle, A.M. Major, et al., Probiotics stimulate enterocyte migration and microbial diversity in the neonatal mouse intestine, Faseb J. 26 (2012) 1960.

[24] J.R. Cole, Q. Wang, J.A. Fish, B.L. Chai, D.M. McGarrell, Y.N. Sun, et al., Ribosomal Database Project: data and tools for high throughput rRNA analysis, Nucleic Acids Res. 42 (2014) D633.

[25] R.C. Edgar, B.J. Haas, J.C. Clemente, C. Quince, R. Knight, UCHIME improves sensitivity and speed of chimera detection, Bioinformatics 27 (2011) 2194.

[26] M. Koch, C. Rudolph, C. Moissl, R. Huber, A cold-loving crenarchaeon is a substantial part of a novel microbial community in cold sulphidic marsh water, Fems Microbiol. Ecol. 57 (2006) 55.

[27] W.W. Esty, The efficiency of good nonparametric coverage estimator, Ann. Statistics 14 (1986) 1257.

[28] C.J. Smith, B.S. Danilowicz, A.K. Clear, F.J. Costello, B. Wilson, W.G. Meijer, TAlign, a web-based tool for comparison of multiple terminal restriction fragment length polymorphism profiles, Fems Microbiol. Ecol. 54 (2005) 375

[29] S. Verma, Anaerobic Digestion of Biodegradable Organics in Municipal Solid Wastes, Department of Earth \& Environmental Engineering: Columbia University, 2002.

[30] Y. Chen, J.J. Cheng, K.S. Creamer, Inhibition of anaerobic digestion process: a review, Bioresour. Technol. 99 (2008) 4044.

[31] F. Monnet, An Introduction to Anaerobic Digestion of Organic Wastes, Final Report, 2003. Remade Scotland.

[32] D.M. Sievers, D.E. Brune, Carbon-nitrogen ratio and anaerobic digestion of swine waste, Trans. Asae 21 (1978) 537.

[33] P. Weiland, State of the art of solid-state digestion-recent developments, in: F.N. Rohstoffe (Ed.), Solid-state Digestion-state of the Art and Further R\&D Requirements, 2006, p. 22. Gulzower Fachgespräche.

[34] A. Khalid, M. Arshad, M. Anjum, T. Mahmood, L. Dawson, The anaerobic digestion of solid organic waste, Waste Manag. 31 (2011) 1737.

[35] E. Allers, C. Niesner, C. Wild, J. Pernthaler, Microbes enriched in seawater after addition of coral mucus, Appl. Environ. Microbiol. 74 (2008) 3274.

[36] J.B. vanLier, Limitations of thermophilic anaerobic wastewater treatment and the consequences for process design, Ant. Van Leeuwenhoek Int. J. General Mol. Microbiol. 69 (1996) 1.

[37] Y. Sekiguchi, Y. Kamagata, K. Syutsubo, A. Ohashi, H. Harada, K. Nakamura, Phylogenetic diversity of mesophilic and thermophilic granular sludges determined by 16S rRNA gene analysis, Microbiology-Uk 144 (1998) 2655.

[38] I. Tiago, I. Teixeira, S. Silva, P. Chung, A. Verissimo, C.M. Manaia, Metabolic and genetic diversity of mesophilic and thermophilic bacteria isolated from composted municipal sludge on poly-epsilon-caprolactones, Curr. Microbiol. 49 (2004) 407.

[39] R. Mullings, J.H. Parish, Mesophilic aerobic gram-negative cellulose degrading bacteria from aquatic habitats and soils, J. Appl. Bacteriol. 57 (1984) 455.

[40] M. Coughlan, F. Mayer, The cellulose-decomposing bacteria and their enzyme systems, in: A. Balows, H. Truper, M. Dworkin, W. Harder, K. Schleifer (Eds.), Prokaryotes: a Handbook on the Biology of Bacteria, second ed., Springer, New York, 1992, p. 460.

[41] D. Lednicka, J. Mergaert, M.C. Cnockaert, J. Swings, Isolation and identification of cellulolytic bacteria involved in the degradation of natural cellulosic fibres Syst. Appl. Microbiol. 23 (2000) 292.

[43] D. Riviere, V. Desvignes, E. Pelletier, S. Chaussonnerie, S. Guermazi, J. Weissenbach, et al., Towards the definition of a core of microorganisms involved in anaerobic digestion of sludge, Isme J. 3 (2009) 700.

[44] A.J.B. Zehnder, Biology of Anaerobic Microorganisms, Wiley, New York, 1988.

[45] R. Wirth, E. Kovacs, G. Maroti, Z. Bagi, G. Rakhely, K.L. Kovacs, Characterization of a biogas-producing microbial community by short-read next generation DNA sequencing, Biotechnol. Biofuels (2012) 5.

[46] D.P. Chandler, F.J. Brockman, T.J. Bailey, J.K. Fredrickson, Phylogenetic diversity of archaea and bacteria in a deep subsurface paleosol, Microb. Ecol. 36 (1998) 37.

[47] L. Bjornsson, P. Hugenholtz, G.W. Tyson, L.L. Blackall, Filamentous Chloroflexi (green non-sulfur bacteria) are abundant in wastewater treatment processes with biological nutrient removal, Microbiology-Sgm 148 (2002) 2309.

[48] Y. Sekiguchi, H. Takahashi, Y. Kamagata, A. Ohashi, H. Harada, In situ detection, isolation, and physiological properties of a thin filamentous microorganism abundant in methanogenic granular sludges: a novel isolate affiliated with a clone cluster, the green non-sulfur bacteria, subdivision I, Appl. Environ. Microbiol. 67 (2001) 5740.

[49] S.R. Vartoukian, R.M. Palmer, W.G. Wade, The division "Synergistes", Anaerobe 13 (2007) 99.

[50] A. Ganesan, S. Chaussonnerie, A. Tarrade, C. Dauga, T. Bouchez, E. Pelletier, et al., Cloacibacillus evryensis gen. nov., sp nov., a novel asaccharolytic, mesophilic, amino-acid-degrading bacterium within the phylum 'Synergistetes', isolated from an anaerobic sludge digester, Int. J. Syst. Evol. Microbiol. 58 (2008) 2003.

[51] S.H. Lee, J.H. Park, H.J. Kang, Y.H. Lee, T.J. Lee, H.D. Park, Distribution and abundance of Spirochaetes in full-scale anaerobic digesters, Bioresour. Technol. 145 (2013) 25.

[52] S.B. Conners, E.F. Mongodin, M.R. Johnson, C.I. Montero, K.E. Nelson, R.M. Kelly, Microbial biochemistry, physiology, and biotechnology of hyperthermophilic Thermotoga species, Fems Microbiol. Rev. 30 (2006) 872. 
[53] H.J. Flint, E.A. Bayer, M.T. Rincon, R. Lamed, B.A. White, Polysaccharide utilization by gut bacteria: potential for new insights from genomic analysis, Nat. Rev. Microbiol. 6 (2008) 121.

[54] S.G. Wan, L. Sun, J. Sun, W.S. Luo, Biogas production and microbial community change during the Co-digestion of food waste with chinese silver grass in single-stage anaerobic reactor, Biotechnol. Bioprocess Eng. 18 (2013) 1022.

[55] C. Sundberg, D. Yu, I. Franke-Whittle, S. Kauppi, S. Smars, H. Insam, et al. Effects of pH and microbial composition on odour in food waste composting, Waste Manag. 33 (2013) 204.

[56] T.L. Miller, C.Z. Lin, Description of Methanobrevibacter gottschalkii sp nov. Methanobrevibacter thaueri sp nov., Methanobrevibacter woesei sp nov and Methanobrevibacter wolinii sp nov, Int. J. Syst. Evol. Microbiol. 52 (2002) 819.
[57] G. Zellner, C. Alten, E. Stackebrandt, E.C. Demacario, J. Winter, Isolation and characterization of methanocorpusculum-parvum, gen-nov, spec-nov, a new tungsten requiring, coccoid methanogen, Archives Microbiol. 147 (1987) 13.

[58] A.G. Hashimoto, V.H. Varel, Y.R. Chen, Ultimate methane yield from beef-cattle manure - effect of temperature, ration constituents, antibiotics and manure age, Agric. Wastes 3 (1981) 241.

[59] C. Gallert, J. Winter, Mesophilic and thermophilic anaerobic digestion of source-sorted organic wastes: effect of ammonia on glucose degradation and methane production, Appl. Microbiol. Biotechnol. 48 (1997) 405.

[60] R.I. Mackie, M.P. Bryant, Anaerobic-digestion of cattle waste at mesophilic and thermophilic temperatures, Appl. Microbiol. Biotechnol. 43 (1995) 346. 